\title{
JOSÉ PATIÑO Y EL CRÉDITO DE FELIPE V ¿UN PROYECTO GLOBAL?
}

\author{
ANNE Dubet \\ Université Clermont-Auvergne - Centre d'Histoire «Espace et Cultures»
}

\begin{abstract}
RESUMEN. El artículo parte de la aparente contradicción entre la política inicial de José Patiño como ministro de Hacienda, basada en un riguroso control de las formas del gasto real, y su acrobática política de crédito desde 1734. Examinando cómo Patiño reforma las instituciones de gobierno de las haciendas peninsular y americanas y cómo trabaja con ellas, intenta reconstituir la coherencia de su proyecto y la forma de integración entre España y las Indias en él. Asimismo, busca calibrar la originalidad de Patiño en relación con sus predecesores.
\end{abstract}

Palabras clave: José Patiño, cardenal Alberoni, Hacienda, crédito, vía reservada, España, Indias.

ABSTRACT. The paper starts from the apparent contradiction between the initial policy of José Patiño as Minister of Finance, based on a rigorous control of the ways of royal spending, and his acrobatic credit policy since 1734. Examining how Patiño reforms government institutions of peninsular and American estates and how he works with them, we try to reconstitute the coherence of his project and the way of integration between Spain and the Indies in it. Likewise, we try to define Patiño's originality in relation to its predecessors.

Keywords: José Patiño, cardinal Alberoni, Finances, credit, vía reservada, Spain, spanish America.

Recibido: 29-1-2020 • Aceptado: 3-4-2020 • anne.dubet@uca.fr 
LA REVISIÓN HISTORIOGRÁFICA del reinado de Felipe V, desde finales del siglo Xx, afectó el significado de uno de sus ministros más longevos y poderosos, José Patiño (Eissa-Barroso y Vázquez Varela, 2013; Lavallé, 2013; Albareda, 2018). Se matizó la imagen del constructor de una marina nacional precursora y un proyecto racionalizador, observando con qué destreza sacó partido de la base clientelar de la monarquía y de la gracia real, y negoció con grupos privilegiados para reforzar la autoridad y los intereses dinásticos de los reyes (Guerrero Elecalde, 2012; Vázquez Gestal, 2013; Storrs, 2016; Glesener, 2018). Asimismo, se revisó su política económica (Delgado Ribas, 2007; Escamilla, 2011; Kuethe y Andrien, 2014; Eissa-Barroso, 2017). En lo relativo al gobierno de la Hacienda, la década de ejercicio de Patiño como ministro de Hacienda y secretario del despacho de Indias y Marina (1726-1736) se enmarca en un período de poca innovación fiscal (Dedieu, 2000 y 2014). Se opta por cambios en el control sobre los productos recaudados y — para fidelizar el crédito- por la negociación con los grupos de negocios más potentes. Así, estos, consolidan posiciones ganadas desde la guerra de los Nueve Años en el arrendamiento de rentas, la provisión militar y la venalidad de oficios y honores (Caro Baroja, 1985; Gainza Gainza, 1999; Aquerreta, 2001; González Enciso, 2007; Andújar Castillo, 2008; Torres Sánchez, 2010; Dedieu, 2011 y 2014).

Desde 1703, esta negociación se hizo esencialmente por la vía reservada de nuevos secretarios del despacho con departamentos y la de algunos ministros principales (Castro, 2004; Pérez-Fernández Turégano, 2006; Andújar Castillo, 2006; Torres Sánchez, 2013 y 2016; Torres Sánchez, 2013; Dubet, 2015a). Desde 1726, sabemos que se institucionaliza un «ministro de Hacienda» en España y la Secretaría de Indias controla la venalidad americana, cambios conducidos por Patiño (Dubet, 2015b; Burgos Lejonagoitia, 2015, pp. 237-246). No obstante, conocemos mal los proyectos de Patiño y sus colaboradores para las instituciones de gobierno de la Hacienda real y el manejo del erario.

¿Quién debía controlar la «distribución de los caudales» — es decir, la decisión sobre los gastos a efectuar y la asignación de los fondos- y el trato con hombres de negocios? ¿Qué margen de beneficios se debía conceder a estos? ¿Qué tipo de deuda preferir? Me centraré en estas cuestiones, partiendo de una aparente contradicción entre dos momentos conocidos del mandato de Patiño. En 1726-1728, el ministro institucionaliza un riguroso sistema de control de los fondos basado en las inseparables figuras del ministro de Hacienda y el tesorero general. La reforma pretende impedir que el tesorero emita de modo autónomo unos efectos de pago que se prestan a peligrosas especulaciones. En 1734-1736, Patiño, desde su ministerio, organiza esta especulación, que servirá de pretexto a la suspensión de pagos de 1739. La política de distribución de fondos y crédito de Patiño para las Indias ofrece otra incógnita. Una 
de las razones es que, con raras excepciones, no se conserva la correspondencia de Patiño con las Indias por la vía reservada en legajos aparte. Por tanto, nuestro hombre aparece poco en estudios de la actividad de los virreyes en la dirección de la Hacienda (Moreno Cebrián, 2000) ${ }^{1}$. Varios aportes monográficos aclaran, no obstante, la forma cómo concebía el uso de la vía reservada y del Consejo de Indias en ciertos ámbitos (Pearce, 1999; Baeza Martín, 2011; Burgos Lejonagoitia, 2015; Eissa-Barroso, 2017). Aportaré complementos relativos a la articulación entre política peninsular y política americana. Mi hipótesis es que la concepción que Patiño tiene del crédito es central en esta articulación y, a la vez, permite resolver la aparente contradicción de su acción peninsular.

Los resultados expuestos utilizan las instrucciones que regían los nuevos órganos creados en la época considerada ${ }^{2}$. Además, estudio las correspondencias del tesorero mayor y los secretarios de Hacienda, Indias y Estado, para reconstruir el significado que diversos actores — entre ellos, Patiño — dieron a los cambios proyectados o llevados a la práctica ${ }^{3}$. Mi exposición será cronológica. Para calibrar su aporte, recordaré lo que hereda del proceso reformador anterior. Abordaré después su política en la península. Me preguntaré, por fin, hasta qué punto la quiso y pudo extender a las Indias.

\section{Proyectos heredados: vía reservada y ministro de Hacienda (1713-1726)}

En 1724, en medio de los conflictos suscitados por el intento de los ministros de confianza de Luis I de crear una forma novedosa de gobierno polisinodial, así como en 1726, cuando el «ministro principal», el duque de Riperdá (enero-mayo de 1726), es blanco de virulentas críticas, franceses instalados en Madrid ven en Patiño el mejor candidato para ocupar la secretaría de Hacienda. En 1726, como se sabe, Riperdá privó a Patiño de la intendencia general de Marina y la presidencia de la Casa de Contratación, intentando alejarlo de España. Patiño aprovecha la desgracia de este. En mayo, ocupa la secretaría de Indias y Marina y el primero de octubre recibe los empleos de Hacienda (secretario del despacho, gobernador del Consejo y superintendente general de la Hacienda). Las reformas de la Hacienda son inmediatas. En octubre, el nuevo ministro instaura la forma de la Tesorería General que promueve entre bastidores

En el trabajo de Escamilla sobre el consulado de México, Patiño aparece esencialmente en el momento de la Junta de Arbitrios formada en 1727 (Escamilla, 2011). No he podido consultar la tesis de Baeza Martín, 2001.

2 Proceden en particular del Archivo Histórico Nacional (en adelante AHN), Fondos contemporáneosMinisterio de Hacienda (en adelante $F C-M H$ ), y el Archivo General de Simancas (en adelante AGS), Dirección General del Tesoro (en adelante DGT).

AHN, Estado (E); AGS, Secretaría y Superintendencia de Hacienda (en adelante, SSH); Archivo General de Indias (en adelante AGI), secciones Indiferente, México y Lima. 
desde el verano. Sigue la reforma afín de la renta del tabaco. Patiño accedió al poder con un proyecto de gobierno bien armado, inspirado en la experiencia de las reformas previas en las que participó (Rodríguez Villa, 1882, pp. 61-62; Pulido Bueno, 1998, p. 217; Dubet, 2015a, pp. 535-586).

\section{a) Las «Nuevas Plantas»}

Este proyecto es fruto de una selección de elementos de las dos «Nuevas Plantas», las de Juan Orry y el cardenal Alberoni. Durante la primera (junio de 1713-febrero de 1715), Patiño contribuyó a la reforma catalana (Pulido Bueno, 1998; Castro, 2004; Pérez Fernández-Turégano, 2006). También asistió a una reforma general del gobierno de la Hacienda — debiendo aplicarla, como intendente - que dejaría una impronta duradera. En esta, sobresalen dos principales aportes. Primero, redujo el poder de los Consejos (tanto el de Hacienda como los de Castilla e Indias) en provecho de sus nuevos Presidentes, unas juntas particulares y los secretarios del despacho (en particular los de Hacienda, Marina e Indias y Guerra), reunidos en un órgano colegial con algunos ministros. En segundo lugar, en la península, la Tesorería Mayor de Guerra erigida en 1703 - una red constituida de un tesorero mayor en Madrid y varios tesoreros particulares agentes del primero, en cada ejército y en algunas plazas militares - devino en Tesorería Mayor a secas, responsable de todo el gasto real (con alguna privilegiada excepción) y encargada de ejercer un riguroso control administrativo sobre los responsables de la recaudación fiscal. Estos solo podían pagar los efectos de pago emitidos por el tesorero y en su nombre. El objeto era privarles de la posibilidad de emitir sus propios efectos (boletines, vales, etc.), ya que con ello se alimentaba una especulación ilícita sobre la diferencia entre su valor nominal y su precio real de reventa entre los particulares, en detrimento del rey —obligado a aceptarlos por su valor nominalPor eso, desde 1713, la Tesorería fue la emisora de efectos que constituían la casi totalidad de la deuda corriente de la monarquía y los ministros encargados de la Hacienda debieron establecer relaciones de confianza con los administradores y arrendadores de contribuciones, sobre cuya fiabilidad descansaba el crédito de la Tesorería. Una de las contrapartidas dadas a los hombres de negocios —en particular, la «constelación» del navarro Juan de Goyeneche (Aquerreta, 2001; Dedieu, 2011) — fue la creación de contratos provinciales de arrendamiento para recaudar lo que pasó a llamarse «rentas provinciales». En cuanto a los intendentes, extendidos ahora a todo el territorio peninsular, se concebían como agentes locales de la vía reservada, encargados de supervisar a cada tesorero particular, agente del tesorero mayor, y velar sobre la recaudación fiscal (Kamen, 1964; Ozanam y Abbad, 1992; Dedieu, 2000; Castro, 2004; Peralta Ruiz, 2006; Dubet, 2015a; Salles Vilaseca, 2016).

La evicción de Orry y sus compañeros, en febrero de 1715, no llevó a liquidar sus reformas. El cardenal Giudice, hombre fuerte hasta el verano de 1716, anuló la 
reforma de los Consejos y redujo las redes de intendentes y tesoreros a las provincias que contaban con ejércitos permanentes, pero preservó la colegialidad y la influencia de los secretarios del despacho y la reforma fiscal (Salles Vilaseca, 2016 y 2018). Desde 1717, Alberoni, nuevo ministro principal, prolongó la reforma de Orry con significativas inflexiones. Así, agravó la reducción de las competencias de los Consejos en materia de Hacienda. En particular, privó al de Indias de los negocios políticos de Comercio, Navegación, Guerra y Hacienda (20 de enero de 1717) a favor de la vía reservada. El de Castilla debió renunciar a enviar «asociados» al Consejo de Hacienda. En paralelo, se potenció la circulación de la información contable por medio de la vía reservada: dos nuevas Contadurías Generales asociadas a ella, las de Valores y Distribución (1 de mayo de 1717), intervendrían todo despacho relativo a pagos, incluso — se precisó- para las Indias, y controlarían a la Tesorería Mayor ${ }^{4}$. En septiembre de 1718, esta dio paso a una Tesorería General. La denominación reflejaba una nueva concepción de su papel: extendida, otra vez, a todas las provincias, con los respectivos intendentes y nuevos «contadores principales», debía absorber las cajas y contadurías locales controladas por las oligarquías municipales. De este modo, se instalaría la vía reservada en el gobierno local de la Hacienda real, minando la influencia de los «poderosos». En particular, los intendentes se concebían a la vez como instrumentos de control más eficaces que visitas y residencias, al ser permanentes, y como intermediarios fiables entre corona y municipios. Aparecían menos tiránicos que los corregidores, cuyas funciones se les asignaron en las capitales de provincias. Patiño, uno de los hombres de confianza de Alberoni y uno de los redactores de la ordenanza de intendentes, suscribía a esta visión (Kamen, 1964; Pulido Bueno, 1998; Castro, 2004; Pérez Fernández-Turégano, 2006; Peralta Ruiz, 2006; Dubet, 2015a). En paralelo, para el gobierno político y militar de plazas estratégicas, tanto en España como en las Indias, se prefirieron los militares, concebidos como instrumentos idóneos de un gobierno «ejecutivo», idea igualmente compartida por Patiño (Gay Escoda, 1982; Giménez López, 1994; Tarragó, 2012; Marchena, 2012; Eissa-Barroso, 2016; Birocco, 2017).

Un último rasgo de la reforma fue la preferencia por el gobierno de individuos. En la cúpula de la monarquía, Alberoni acabó con la colegialidad de los secretarios del despacho. Subsistieron tres, responsables de departamentos organizados por materia que abarcaban toda la monarquía. En la práctica, solo dos de ellos, el de Gobierno Político, Gracia, Justicia y Hacienda, José Rodrigo Villalpando, y el de Guerra y Marina, Miguel Fernández Durán, segundaron activamente al cardenal. Este se erigió en

Órdenes de 19/08/1717 y 25/10/1725. AGI, Indiferente, leg. 542, fols. 25 y 28, y legs. 992 y 989. Decreto de 01/05/1717, AHN, FC-MH, libro 8011, núm. 304. Necesitamos monografías sobre estas Contadurías para saber en qué grado aplicaron las directivas en el ámbito indiano. 
intermediario entre ellos y el rey — lo lamentó Patiño a posteriori- Quedó marginado José Grimaldo, secretario de Estado (Gildas, 1972; Escudero, 2001; Castro, 2004). En el gobierno de rentas, se abolió la junta de rentas generales (el conjunto de aduanas), sustituida por un superintendente general en 1716, empleo dado en 1717 al marqués de Campoflorido con el gobierno del Consejo de Hacienda. Según este, el manejo de uno solo, con tal que fuera «inteligente» en materia de Hacienda, era más provechoso que el de un órgano colegial (Dubet, 2015a). El mismo año 1717, Alberoni instituyó un monopolio del tabaco como ramo aparte en Cuba y sustituyó a la junta de azogues (1708) un superintendente general de azogues de la monarquía elegido en el Consejo de Indias. En 1719, se creó un superintendente general del ramo para Perú (Kuethe, 2013; Pearce, 1999). En cuanto a Patiño, recibió a la vez la intendencia del reino de Sevilla y el ejército de Andalucía, la presidencia de la Casa de Contratación y la intendencia de Marina, de nueva creación (1717), por lo que cabe suponer que ideó la reforma (Pulido Bueno, 1998; Dedieu, 2000; Pérez Fernández-Turégano, 2006). En 1718, también se instituyeron superintendentes de las casas de moneda peninsulares, imponiéndoles formas de control contable similares a las usadas en las agencias locales de la Tesorería General. Los primeros superintendentes estarían a las órdenes del tesorero general, Nicolás de Hinojosa, «a quien tengo encargado (sic) la dirección, correspondencia y fábrica de la moneda». Sin duda, se quería ampliar la base financiera del tesorero 5 . En los virreinatos indianos, el decreto de 20 de enero de 1717 quitaba a las Audiencias la participación en la atribución de encomiendas.

Alberoni y su equipo, por tanto, parecían pensar que los mismos órganos (superintendentes dependientes de la vía reservada) podrían servir en toda la monarquía para instituir un gobierno de la Hacienda de los «inteligentes», reduciendo el poder de los letrados de los órganos colegiales. Patiño recordaría la idea. No obstante, el Consejo de Indias salió mejor parado que los de Castilla y Hacienda, conservando el patronato regio, fuente de poder y riqueza (Alcaraz Gómez, 1995). Además, la proyección local del gobierno de la Hacienda en América resultó ambivalente. Así, los virreyes ganaron prerrogativas: se invitó al de Nueva España a negociar los arrendamientos solo, sin las Audiencias y oficiales reales (Heredia Herrera, 1989, p. 493) ${ }^{6}$; el del nuevo virreinato de Nueva Granada debía imponer el orden a los oficiales de las cajas reales (Eissa-Barroso, 2017). Pero los virreyes perdieron la concesión de encomiendas y, en Perú por lo menos, la dirección del ramo de azogues. Esta vacilación podría reflejar condiciones locales, pero también divergencias en el equipo de Alberoni

Ordenanza de 26/01/1718, firmada por José Rodrigo. AHN, Consejos, leg. 12740, exp. 6. Títulos de los nuevos intendentes y tesoreros: AGS, DGT, inventario 24, leg. 434.

Marqués de Casafuerte al rey, 28/05/1727, AGI, México, leg. 494.

Así, Rodrigo Villalpando, defensor de los intendentes en España (Kamen, 1964), quería crearlos en las Indias, «independientes de los virreyes», proyecto que tendría contradictores. Biblioteca Nacio- 


\section{b) La consolidación de la reforma}

La caída de Alberoni, a fines de 1719, acarreó persecuciones políticas, afectando brevemente a Patiño ${ }^{8}$ (Máqueda Abreu, 2009). También conllevó una nueva inflexión en la reforma. En enero de 1721, se restableció un conjunto de cinco secretarios del despacho similar al de 1714. De este modo, la Hacienda se repartía entre el secretario de la Hacienda (España) y el de Indias. Por fin, como concesión a las oligarquías locales y al Consejo de Castilla, se redujeron las redes de intendentes, contadores y tesoreros a las provincias con ejércitos permanentes, como en 1715. Solo subsistieron los intendentes, reducidas sus facultades a las de los corregidores (Kamen, 1964).

El cambio reflejaba el conflicto entre antiguos colaboradores de Orry y Alberoni. El regreso a una Tesorería Mayor manifestó la victoria de Camploflorido sobre Hinojosa. El primero condenaba la excesiva autonomía del tesorero. Le reprochó en particular el recurrir a cambistas para hacer sus pagos, en lugar de atenerse a los arrendadores de rentas provinciales, más fiables y propensos a preservar el secreto del rey. Tampoco admitía que todos los secretarios del despacho dieran órdenes a este tesorero. Su proyecto, explicado entre 1721 y 1725, era el de un «ministro de Hacienda» que reuniera las competencias y empleos del secretario de Hacienda - la distribución de los caudales, que englobaba el trato con arrendadores y asentistas-, del gobernador del Consejo de Hacienda - la supervisión de la actividad contenciosa - y del superintendente general de la Hacienda — la recaudación fiscal—. Este ministro debía ser «inteligente» en materia de Hacienda, pudiendo así tratar con hombres de negocios, previniendo sus fraudes, y dirigir de modo adecuado al tesorero mayor. En el territorio, quería que los intendentes conservasen las funciones enunciadas en 1718, en todas las provincias. Campoflorido obtuvo parte de lo que pedía. En 1721, se le dieron los tres empleos, pero no la superintendencia de la renta del tabaco, que también reclamaba. En 1723, obligó a los demás secretarios a reunirse con él para preparar el «estado de cargas» anual, un plan provisional para la distribución. Además, desde 1721, la secretaría de Hacienda consolidó su autoridad sobre intendentes y tesoreros de ejércitos (Torres Sánchez, 2012). Buena señal de la trascendencia del cambio es la oposición que suscitó el ministro de Hacienda. Según el gobernador del Consejo de Castilla, Luis de Miraval, revelaba un gobierno despótico (Delgado Barrado, 2007; Dubet, 2015a). No obstante, la alternativa probada por Miraval durante el reinado de Luis I — un gobierno colegial de los letrados— apenas afectó al ministro de Hacienda.

nal de España, ms 18055, fols. 186-94 (fols. 192-193). La fecha de 1716 indicada en esta copia es errónea. Eissa-Barroso demuestra que el discurso es posterior a la reforma aduanera de 1717 (2017, pp. 211-13).

$8 \quad$ Perdió sus empleos, recuperándolos en septiembre de 1720 gracias a Grimaldo, quien recobraba la confianza real. AHN, E, leg. 533. AGS, Guerra Moderna, leg. 2357. 
El nuevo secretario de Hacienda, Fernando Verdes Montenegro, reducido teóricamente al trámite de papeles, siguió controlando la distribución de fondos. Además, ideó una traducción institucional de la idea de Campoflorido en un proyecto de planta del tesorero mayor: el ministro de Hacienda sería el único en comunicar órdenes al tesorero; este sería sometido a un control añadido, el de un nuevo contador de su cajero principal, y la validez de los efectos impagados que cada tesorero saliente transmitía a su sucesor dependería de un «páguese» del ministro (Dubet, 2015a). Letra muerta en 1724 , el proyecto sedujo a Patiño.

La suerte de las reformas americanas desde 1721 es más difícil de calibrar. En 1723, el Consejo de Indias abolió el virreinato de Nueva Granada, por hostilidad a la vía reservada que lo creara (Eissa-Barroso, 2017). En cambio, no pareció anularse el decreto de 1717 que le privaba de los negocios de Comercio, Navegación, Hacienda y Guerra y sobrevivieron los superintendentes de azogues. No se sabe, finalmente, si el marqués de Valero, colocado por Miraval a la cabeza del Consejo de Indias en 1724, intentó introducir en el gobierno de las Indias cambios afines al proyecto de su protector (Dubet, 2015a, p. 178). Una carta del visitador general de Nueva España sugiere una respuesta positiva, sin ofrecer detalles ${ }^{9}$. En suma - por ignorancia nuestra-, el balance parece matizado. En febrero de 1726, los contadores mayores de Indias afirmaron al Consejo que la creación de los contadores generales de valores y distribución de 1717 les impedía acceder a parte de la documentación necesaria para preparar relaciones de valores de las rentas americanas ${ }^{10}$. Si hay algo de captatio benevolentiae en el argumento, cabe atribuirle un fondo de verdad, ya que sus autores se dirigían a gente bien informada. No obstante, sería deseable contar con estudios de la actividad cotidiana de los dos predecesores de Patiño en la secretaría de Indias para conocer lo que quedó de la reforma de la vía reservada de Indias de Alberoni. Aun así, se entiende por qué, en 1726, Patiño no llegó con las manos vacías, apoyándose en los logros e ideas de sus predecesores.

\section{Talentos de un ministro}

En 1726, Patiño no es un novato en el control de la Hacienda. Como intendente general de Marina desde 1717, preparó nuevas reglas de control contable de las obras navales y la Marina. Destacan las instrucciones dadas a «los intendentes y demás ministros de Marina» en enero de 1725. Estas presentan afinidades con la forma del control ejercido mediante la Tesorería Mayor, al descansar en la vigilancia recíproca de intendentes, comisarios ordenadores y tesorero y usarse técnicas y formularios afi-

Francisco de Garzarón a Casafuerte, 02/05/1725. AGI, México, leg. 494.

10 Los contadores al Consejo, 01/02/1726. AGI, Contadurías, leg. 1790. 
nes. Así, Patiño acompaña el cambio en las prácticas contables (Teijeiro de la Rosa, 2002; Pérez Fernández-Turégano, 2006). Lo que me interesa, no obstante, es la dimensión política de su proyecto. Aquí, el modelo viene dado por los dos precedentes secretarios de Hacienda, Campoflorido (1721-febrero de 1724) y Verdes Montenegro (febrero-octubre de 1724).

Las primeras disposiciones de Patiño en su calidad de secretario del despacho de la Hacienda precisan y amplían los contornos de sus responsabilidades. Como desde el primero de octubre Campoflorido es a la vez gobernador del Consejo de Hacienda, superintendente general de rentas generales y secretario del despacho de Hacienda, «con la distribución de caudales», o sea con la «facultad de disponer y distribuir todos los caudales así de España como de los que llegaren de Indias y procedieren de comercio de ellas, derechos de entrada y salida y otros» (o sea los fondos remitidos a la Depositaría de Indias, pero no los recaudados y gastados en América) ${ }^{11}$, poco después (el 30 de diciembre), Patiño firma la nueva planta de la Tesorería, calificada de modo indiferente de «Mayor» o «General» desde la fecha. Esta recupera la forma que tuvo hasta diciembre de 1725, después de unos meses en que Hinojosa experimentó una fórmula inédita que le confería una importante autonomía. Patiño sin duda contribuye a su caída. La nueva planta copia a la letra las innovaciones ideadas por Verdes Montenegro en 1724. Destacan dos. $1^{\circ}$ ) El monopolio de la autoridad sobre el tesorero conferido al secretario de Hacienda, excluyendo a los demás secretarios del despacho. $2^{\circ}$ ) El control sobre el crédito, mediante la creación de un contador encargado de intervenir al cajero principal de la Tesorería Mayor en Madrid y la necesidad, para cada tesorero mayor entrante, de obtener la validación del ministro, bajo la forma de un «páguese», para proceder a librar los efectos impagados que le dejó el tesorero saliente. De este modo, se refuerza el control sobre tres vías de creación de deuda: a) las cartas de pago provisionales que el tesorero emite «sobre» (como dice la documentación) administradores y arrendadores de impuestos —aquí, sirve el «páguese»—; b) los boletines que el tesorero emite sobre su cajero principal en Madrid; y c) los vales que el propio cajero da a acreedores — aquí, obra el nuevo contador de la caja-. Por otra parte, la planta describe las modalidades de la circulación de información contable entre tesoreros locales y tesorero general, debiéndose destinar estados regulares al ministro de Hacienda ${ }^{12}$.

\section{a) Imitación e innovación}

Se podría concluir que la originalidad de Patiño no reside en las ideas, sino en su capacidad para institucionalizar el esquema pensado por sus predecesores. Es in-

Decreto y cédula de 09 y 23/10/1726. AHN, FC-MH, libro 8012, núm. 459.

12 Planta de 30/10/1726. AHN, FC-MH, libro 7933, fols. 85-105 y AHN, E, libro 884. 
negable que tiene la capacidad política y económica para hacerlo. En efecto, combina el apoyo de la reina y el soporte que le ofrece la red de Campoflorido, a la que parece heredar (Vázquez Gestal, 2013). Como se sabe, Juan de Goyeneche y su grupo son a la vez los jefes de las casas de negocios de mayor crédito, que controlan parcelas importantes del arrendamiento de rentas y la provisión militar, individuos influyentes en la corte y en Consejos y secretarías y, para algunos, fabricantes de opinión económica (Guerrero Elecalde e Imízcoz Beunza, 2012; Imízcoz Beunza, 2017; Dubet, 2015a; Dubet y Solbes Ferri, 2019). La señal más visible de su buena relación con Patiño es la elección como tesorero general del sobrino de Goyeneche, Tomás de Iriberri, quien fuera hasta la fecha tesorero general de las rentas generales. Ejerce dos mandatos, desde octubre de 1726 a septiembre de 1727 y desde diciembre de 1729 a fines de 1733 .

Pero Patiño da más pruebas de su buena voluntad al grupo. En primer lugar, en marzo de 1727, elige como sustituto de Iriberri en las rentas generales a Félix López de Ortega, probable pariente de Pedro López de Ortega, administrador de la casa de Valdeolmos, compañero habitual de Goyeneche desde la guerra ${ }^{13}$ y protegido de Campoflorido. En segundo lugar, hace una magna operación de crédito con otro compañero de Goyeneche, el marqués de Santiago. La idea no es nueva. Ya en 1725, un grupo liderado por Juan Bautista de Iturralde, socio y amigo íntimo de Goyeneche, hizo con el rey una operación jugosa, comprándole la «renta de población» de Granada con cláusula de restitución (Dubet, 2016a). En su memoria programática al rey, a fines de 1726, Patiño anuncia su intención de reiterar el experimento: como en Granada, se podrían sacrificar «alhajas» de la corona por dos millones de escudos ${ }^{14}$. No pierde tiempo, aunque debe rebajar el precio. En 1727, se concierta la venta de rentas valencianas a Santiago, por «juro de heredad», por 1,66 millones de escudos ${ }^{15}$. En tercer lugar, Patiño autoriza la creación de la compañía guipuzcoana de Caracas, entrando en ella Goyeneche y sus amigos (Garate Ojanguren, 1990, pp. 73-74). Además, la «constelación» de Goyeneche conserva posiciones adquiridas, en particular en las rentas provinciales, la provisión de víveres de Marina y la del ejército de tierra, en la que Pedro López de Ortega alterna hasta 1729 con un grupo rival, el de Urban Ruiz Velarde.

\footnotetext{
13 Actoz (https://actoz.db.huma-num.fr/fmi/webd/Actoz_actions). Sobre el vínculo entre Goyeneche y Valdeolmos: Aquerreta, 2001.

14 «Memoria presentada al señor don Felipe por don José Patiño el año de 1727». Canga Argüelles, 1833-1834, II, p. 121.

15 «Lo que se asienta y concierta entre el Ilustrísimo señor don Joseph Patiño [...] de la una parte y de la otra el señor don Francisco Esteban Rodríguez de los Ríos, marqués de Santiago [...], sobre la venta y compra de los Tercios diezmos de la Ciudad y Reino de Valencia y de las bailías de Beniganin, Villareal y Villajoyosa que andan arrendadas unidamente con ellos», 10/01/1727. A 21/04/1727, Felipe V manda redactar la escritura de venta. Se publica la cédula a 27/06/1727. AHN, Consejos, leg. 11542, exp. 611, núm. 2.
} 
Sin embargo, Patiño no se atiene al apoyo navarro. Ya en 1727, tiene excelentes relaciones con Mateo Pablo Díaz de Lavandero, un hombre de negocios bien implantado en Sevilla, donde es veinticuatro y arrienda rentas generales y salinas, con conexiones familiares útiles en Galicia. Asimismo, cultiva la fidelidad de Ventura de Pinedo, tesorero de la Cruzada. Esta relación personal, sin duda, le facilita el acceso a esta renta separada de la Tesorería General, regida por condiciones impuestas por el papa. Cuando en 1726 Patiño reforma la renta del tabaco, Pinedo y Díaz Lavandero pasan a ser directores de ella. También participa en los negocios del rey César Rubini, muy activo en la década de 1720, por lo que, cuando pone las rentas generales en administración directa (1734), Patiño acude a él (Dubet y Solbes Ferri, 2019, p. 160) ${ }^{16}$. En 1728, el ministro arrienda la renta de salinas, administrada desde 1714, confiándola a Pedro Francisco Peña, socio de Ruiz Velarde, rival de los navarros ${ }^{17}$. Esta disposición, lo mismo que la decisión de hacer de Díaz Lavandero el tesorero alternante de Iriberri desde 1728, podría responder a una estrategia tendente a reducir el dominio de los navarros sobre los negocios del rey, que se busque suscitar una competencia o solo multiplicar los recursos.

El talento de Patiño, no obstante, no se limita a su destreza en recuperar las ideas de los demás y valerse, para aplicarlas, de apoyos heredados o nuevos. En un análisis de sus primeros meses de actividad, mostré cómo, además de entender el proyecto de sus predecesores, le da mayor cobertura institucional. Así, redondea sus facultades de ministro de Hacienda, obteniendo en particular la de negociar con deudores morosos (abril de 1727), dada luego a los secretarios del despacho sucesivos. Por otra parte, eleva su control sobre una de las rentas más fructíferas de la corona, la del tabaco. En noviembre de 1726, sustituye a su superintendente con dos órganos, una terna de directores encargada del «gobierno» y una junta responsable de lo «gobernativo y providencial», lo «contencioso y de justicia» y lo «consultivo» ${ }^{18}$ (Escobedo Romero, 2007, pp. 29-37). Le corresponde al propio Patiño proponer candidatos para los principales empleos, en particular el tesorero general de la renta, y dar órdenes para que este remita dinero al tesorero general de España. Así, su control es más inmediato que el ejercido por los ministros de Hacienda anteriores. En diciembre, la instrucción para la administración de la renta formaliza su integración al sistema de control contable

\footnotetext{
16 Quedan por investigar los usos financieros de la renta de la Cruzada: López Díaz, 2016.

17 El proyecto se contempló desde 1725. AHN, E, libro 881 y AHN, E, leg. 751. La oferta de Peña se acepta en mayo de 1728 para Castilla la Vieja, Murcia, Badajoz, Zamora, Aragón, Galicia, Asturias. Los navarros Miguel de Arizcun y Mateo de Herroz conservan las salinas de Andalucía. Las de Cataluña se administran. AGS, SSH, legs. 212-1 y 212-2. AHN, E, libro 904, fols. 293-299. Los navarros, no obstante, recuperan posiciones en Galicia y Asturias (con Carlos Domingo Brea, socio de Herroz, en 1730) y en Atienza (con Pedro López de Ortega). AGS, SSH, legs. 216-1, 216-2, $217-1$. Esta delimitación se fue precisando con el tiempo.
} 
encabezado desde 1713 por la Tesorería General de España (Dubet, 2012 y 2013). Por otra parte, Patiño agrava el control sobre el tesorero general. En septiembre de 1727, decide que su ejercicio será anual y alternante desde octubre y, en 1728, extiende la regla a los tesoreros particulares, o sea los agentes del tesorero en las provincias con ejércitos. El objetivo es obligarles a presentar los efectos que permanezcan impagados al concluir su ejercicio, para evaluar la deuda corriente y prevenir fraudes. Patiño se ocupa personalmente de poner en obra parte de estas disposiciones, explicándolas y reiterándolas (Dubet y Solbes Ferri, 2019).

\section{b) Una aparente contradicción}

Esta tenacidad de Patiño a la hora de consolidar su control sobre la distribución de los caudales, en general, y el tesorero, en particular, no se debe malinterpretar, atribuyéndose a un deseo de centralizar la administración de la Hacienda real para erradicar de ella negocios ilícitos tradicionalmente atribuidos a la corrupción de los actores privados. En efecto, si este fuera el caso, se debería pensar que el ministro no tarda en contradecirse. Primero, los tesoreros particulares observan la anualidad, pero no sus jefes: el segundo tesorero general, Díaz de Lavandero, ejerce dos años (octubre de 1727-noviembre de 1729); le sucede Iriberri durante cuatro años; regresa Díaz de Lavandero desde 1734 hasta la muerte de Patiño. En segundo lugar, desde 1734 por lo menos, Patiño organiza, con la colaboración de la tesorería lo que quiso prohibirle en 1727-1728. En efecto, mediante órdenes del rey emitidas por la vía reservada de Hacienda de Patiño, un tal Martín de Herce, que se intitula «agente general de la Tesorería General» (el empleo no figura en las plantas de la Tesorería), «beneficia»—vende por debajo de su valor nominal - cartas de pago provisionales del tesorero general para allegar fondos, «así en dinero efectivo como en diferentes letras [de cambio]». Entre los efectos vendidos, figuran importantes cartas de pago sobre la renta del tabaco (Dubet, 2017; Dubet y Solbes Ferri, 2019). No se encontraron explicaciones de Patiño sobre estas «negociaciones». Sí comenta la no aplicación de la anualidad a los tesoreros mayores. Cuando Iriberri le recuerda que se debe ponerla en obra, le espeta que es inoportuno consultar la cuestión con el rey ${ }^{19}$. Así, no explica nada, pero revela que la inobservancia estuvo calculada.

De este modo, Patiño nos ofrece un indicio de su constancia, invitándonos a reconsiderar el significado de su esfuerzo inicial por elevar el control ejercido por el ministro de Hacienda sobre la distribución de fondos. En mi opinión, su motivo más

«considero no llega aun el caso de hacer presente la referida representación, que queda por ahora en mi poder para usar de ella como convenga en sazón oportuna». Carta de 20/10/1730, respuesta a la de 09/10. AGS, SSH, leg. 217-2. 
importante, tanto en 1726 como en la década siguiente, es su convicción de que el crédito de la monarquía es una cuestión política. Por tanto, todo su empeño consiste en ponerlo en manos del ministro, y no del tesorero general, aunque corra el riesgo de fragilizar la credibilidad de este. Esta lógica no excluye los negocios escabrosos, con tal que el ministro los controle y piense que serán benéficos para el rey. La relación de trabajo que Patiño establece con el tesorero hasta 1730 alimenta esta interpretación.

\section{El crédito del rey, obra del ministro}

Para Patiño, sostener el crédito es el imperativo esencial. Llama la atención que, en su memoria programática de 1726, empiece clasificando las deudas en función del grado de obligación del reembolso. Cita como ejemplo a seguir las vecinas Francia, Inglaterra y Holanda que, explica, separaron algunas rentas de la «actual manutención de la corona» para dedicarlas al reembolso e invita al rey a apartar de las demás las deudas cuyo reembolso puede esperar. En cuanto al fondo disponible cada año, Patiño sabe que no suele gastarse directamente, sino que los hombres de negocios anticipan el dinero necesario para el gasto corriente, por lo que es justo premiarlos con «adehalas». Por eso importa buscar ministros «bien vistos en el comercio», para que traten con estos acreedores (Canga Argüelles, 1833-1834, II, pp. 121-125). Así, el objetivo no es pagar las deudas ni menos llegar al equilibrio presupuestario, sino crear un marco de confianza para poder diferir el pago de las deudas y seguir consiguiendo anticipaciones.

\section{a) La Tesorería, interfaz del crédito}

Ahora bien, Patiño tiene claro que la Tesorería General es el órgano idóneo para organizar esta relación de confianza con los hombres de negocios, aunque, como veremos, no es la única. Lo muestran las primeras disposiciones aplicadas a la Tesorería y lo confirma el que el tema casi único de su correspondencia con los sucesivos tesoreros sea la atribución a diversos acreedores de cartas de pago provisionales sobre diversas rentas. En esta operación, Patiño y los tesoreros tienen claro que ciertas rentas son más interesantes que otras. Con las rentas provinciales, existen usos bien establecidos, dedicándose algunas de ellas a gastos específicos, como la manufactura de Guadalajara, ciertos asientos de provisión o los ejércitos presentes cerca de la misma provincia. Desde su creación en 1714 , se paga a los arrendadores un $8 \%$ por la «conducción» de los fondos a la corte, tarifa regulada (Dubet y Solbes Ferri, 2019). En ciertas ocasiones, sin embargo, la renta del tabaco resulta más interesante. Ya en su memoria de 1726, Patiño consideró que era una de las más prometedoras, pudiéndose como mínimo duplicar su producto (Rodríguez Gordillo, 2008). Otra ventaja: el pago con el producto del tabaco cuesta barato. En 1729, Iriberri señala que, recurriendo a la renta para remitir 
dinero a Galicia, evitaría pagar «conduciones (sic) y cambio de letras desde Madrid» ${ }^{20}$. En julio de 1730, Patiño remite así fondos del tabaco a Navarra y Granada, porque el arquero general de la renta (en aquellas fechas, no se le llama tesorero) explicó que el traslado se haría «en especie ligera, sin coste alguno de reducción» ${ }^{21}$. Convendría multiplicar los indicios de esta convicción de Patiño de las ventajas de la renta para los pagos hechos en nombre de la Tesorería General ${ }^{22}$, pero llama la atención que, confrontado a «cierta urgencia del servicio», recurra en seguida a ella ${ }^{23}$.

El otro fondo útil es el custodiado por las casas de moneda que, desde 1713, también hacen pagos bajo el control de la Tesorería General. A principios de 1728, el tesorero general Díaz de Lavandero hace un balance de los pagos librados en el "caudal de flota», distinguiendo lo que está por pagar y lo ya pagado. Ahora bien, el $46 \%$ de lo pagado se libró en la casa de moneda de Segovia, distribuyendo el resto el Presidente de la Casa de Contratación, probablemente en la Depositaría de Indias (separada, en aquel entonces, de la Tesorería General) ${ }^{24}$. El tesorero no describe las asignaciones de las cartas de pago provisionales que esperan a ser pagadas, pero señala que las dadas al mayor acreedor, Juan Bautista de Iturralde, se pagarán en la casa de moneda de Sevilla ${ }^{25}$. Otros consideran que esta casa de moneda es una buena consignación. Cuando falla el reembolso que el asentista de la provisión de víveres de la expedición de Gibraltar, Urban Ruiz Velarde, tenía asignado en las rentas provinciales de Sevilla, el interesado pide una carta de pago sobre la casa de moneda de Sevilla ${ }^{26}$. El del vestuario, Blas Manrique, recibe idénticos efectos por iguales razones en 1730. El propio Patiño le explica entonces que es un pago seguro porque él dio «ejecutiva disposición» para que se efectuase ${ }^{27}$. Esta confianza en las rentas del tabaco y las casas de moneda podría explicar por qué Patiño presta una particular atención al control contable sobre ambas administraciones. Ya lo vimos con la renta del tabaco. Las casas de moneda son objeto de nuevas regulaciones contables con ocasión de la reforma de la ley de las monedas de 9 de junio de 1728, completada a 16 de julio de 1730. Como en el caso de la renta del tabaco, se precisan las modalidades de la justificación de los pagos que hacen estas casas en nombre del tesorero general ${ }^{28}$. En ambos casos, un

Carta de diciembre de 1729, Madrid, AGS, SSH, leg. 216-1.

O sea, cambio de monedas. Patiño a Iriberri, Cazalla, 12/07/1730. AGS, SSH, leg. 217-1.

En todo el siglo, la renta del tabaco se considera como una de las mejores bases para el crédito del rey. González Enciso, 2000. Torres Sánchez, 2006 y 2013.

23 Patiño a Ventura de Pinedo, director de la renta, Cazalla, 25/05/1730. AGS, SSH, leg. 216-2.

24 Cartas y relaciones enviadas a Patiño, 15/02/1728. AGS, SSH, leg. 212-1. La Depositaría de Indias se integró a la red de Tesorería General en 1751. Torres Sánchez, 2012, pp. 40-41.

25 Díaz Lavandero a Patiño, Madrid, 24/02/1728. AGS, SSH, leg. 212-2.

26 Díaz Lavandero a Patiño, Madrid, agosto de 1728. AGS, SSH, leg. 212-1.

27 Patiño a Manrique, Castelblanco, 11/02/1730. AGS, SSH, leg. 216-1.

28 AGS, DGT, Inv. 24, leg. 434.
} 
primer motivo de las reformas es dar al tesorero y al ministro la información necesaria para que organicen la distribución de fondos tan útiles al crédito del rey.

\section{b) El ministro, jefe de la Tesorería y garante del crédito}

Ahora bien, aunque gran parte de los pagos se hacen con efectos del tesorero general, el verdadero crédito depende el ministro. Patiño lo cree y los hombres de negocios deben admitirlo. Esta convicción sale a luz cada vez que se producen fallos en los pagos. Así, en 1730, Iturralde, quien suele dar importantes letras de cambio para Barcelona, explica a Iriberri que suspendió el pago de las últimas porque las cartas de pago dadas por el tesorero general sobre ciertas rentas para su reembolso «se reconocieron fallidas». El hombre de negocios exige garantías seguras, en tono displicente, sea porque le unen a Iriberri afinidades que le permiten ser franco, sea porque, siendo uno de los mayores acreedores del rey, puede presionarlo ${ }^{29}$. Ahora bien, aunque el reproche se dirige al tesorero, Iturralde solicita la garantía del ministro: Iriberri debería poder «facilitarle» una orden oportuna de Patiño para que se le pague con cualquier «residuo» de la renta del tabaco de 1729 o con el producto de 1730. Patiño lee la reclamación en clave política, indignándose. Atribuye la osadía de Iturralde a la distancia física («confiado en la distancia que obliga a pasar muchas veces por cosas injustas»), estando el rey en Andalucía. Si este último estuviese en Madrid, añade, la cosa no pasaría desapercibida. Sin embargo, escribe en seguida a un director de la renta del tabaco para que pague las cartas de pago que le vaya mandando el tesorero general. Por su parte, según Iriberri, Iturralde hace acto de contrición ${ }^{30}$. Meses más tarde, cuando Patiño desea obligar a los hombres de negocios a pasar un contrato con la corona para el envío regular de letras de cambio a Barcelona, Iriberri solicita a Iturralde, pero este reclama «primero alguna insinuación de Vuestra Excelencia [Patiño] para complacerle $»^{31}$. La palabra del ministro prima sobre la garantía del tesorero.

Esta autoridad del ministro impone un trabajo intenso a Patiño y los oficiales de la secretaría de Hacienda. En efecto, el ministro decide sobre la asignación de los pagos en las rentas, basándose en la información facilitada por el tesorero sobre el estado de estas y la procedente de las rentas. Una vez tomada la decisión, cada pago requiere redactar múltiples cartas. Por ejemplo, en 1730, Patiño decide remitir una

\footnotetext{
$29 \quad$ El negocio «no deja ensanches ni arbitrios para superar ninguna dilación o falencia en los efectos que se reciben y menos permiten que se traten con expresiones generales como las que Vuestra Señoría me ha manifestado en este asumpto (sic), debiendo caminarse en él con la positiva seguridad que corresponde a su importancia por lo que se interesa el más puntual servicio del rey». Iturralde a Iriberri, Madrid, 21/01/1730, AGS, SSH, leg. 216-1.

Cartas de 21, 26, 26 y 30/01/1730. AGS, SSH, leg. 216-1.

Iriberri a Patiño, Madrid, 02/10/1730. AGS, SSH, leg. 217-2.
} 
cantidad mensual a la mina de Almadén repartida entre las rentas provinciales de la Mancha y de Jaén (arrendadas por Mateo de Herroz y Miguel Francisco de Aldecoa) y la renta del tabaco. El pago se hará con cartas de pago provisionales de Iriberri sobre las futuras mesadas, a favor de los dos arrendadores de rentas provinciales y del arquero general del tabaco. En el caso de las rentas provinciales, quien presente los efectos del tesorero general a los arrendadores será «la persona que corre con los caudales» de Almadén. En el caso de la renta del tabaco, Iriberri enviará su carta de pago a uno de los directores de la renta, Pinedo: este le mandará al arquero general emitir sus propias cartas de pago para que el recaudador local del tabaco dé el dinero al responsable de Almadén. Son oficiales de la secretaría quienes verifican que las rentas provinciales designadas tienen disponibilidades para soportar el pago, antes de formalizar las órdenes necesarias. La capacidad de la renta del tabaco no se cuestiona, pero Pinedo la comprobará. En total, para esta sola operación, Patiño y sus oficiales escriben al superintendente de la mina de Almadén, al director de la renta del tabaco, a ambos arrendadores de rentas provinciales $y$, por supuesto, al tesorero general ${ }^{32}$.

\section{c) La difícil coordinación}

Esta concepción de los papeles respectivos del ministro y del tesorero acarrea problemas prácticos y tensiones. En efecto, el procedimiento normal debería ser que el ministro dirija al tesorero un proyecto de ventilación de los pagos a efectuar sobre las rentas disponibles, antes de que este emita las cartas de pago necesarias, aplicándose después el programa. La realidad es más compleja. Patiño se dirige a menudo directamente a los acreedores de la corona, prometiéndoles cartas de pago del tesorero sobre ciertas rentas, cuando este tenía previstas otras consignaciones, basadas en un plan anterior del ministro. Cada vez que se produce el caso, Patiño impone su autoridad. Así, en enero de 1730, Iriberri se niega a dar a un asentista parte del producto de las rentas provinciales de Palencia, porque ya están consignadas a Iturralde. Reacción fulgurante de Patiño: Iriberri debe cumplir «sin más réplica ni dilación», entretanto que el ministro — que no el tesorero- escribirá a Iturralde para ofrecerle «otro efecto igualmente seguro» ${ }^{33}$.

La repetición de tales episodios causa fricciones entre Patiño e Iriberri. Cuando, en febrero de 1730, el asentista el vestuario, Manrique, se queja de que no se le pagan cartas de pago sobre las rentas provinciales de Sevilla, Iriberri explica a Patiño que él, el ministro, causó el fallo, al destinar las mismas mesadas de la renta al tesorero de guerra de Andalucía, obligando al tesorero general a buscar otra consignación para

Cartas redactadas en Castelblanco, 29/01/1730, AGS, SSH, leg. 216-1.

Patiño a Iriberri, Sevilla, 07/01/1730. AGS, SSH, leg. 216-1 
el asentista. Patiño le devuelve el cumplido: Iriberri debe presentarle lo cierto como tal y lo incierto como tal. El tesorero no se deja impresionar: explica los cambios de asignación que debió hacer en la urgencia, recordándole al ministro que ya le informó por escrito ${ }^{34}$. El diálogo sube de tono cuando Patiño exige que Iriberri respete a la letra un estado del fondo destinado a las guardias del rey preparado en su Secretaría, «en la forma y rentas que en él están aplicadas sin que se varíe por ningún motivo». En la misma carta, Patiño exige que Iriberri explique cualquier cambio con todo detalle, dando la lista de los justificantes a ofrecer. La respuesta suena a reproche: Iriberri le ruega a Patiño que mande «que así los repetidos avisos que sobre ellos tengo hechos a Vuestra Excelencia y relaciones remitidas del estado de las rentas se examinen para que por ellas se halle Vuestra Excelencia enterado» del estado de los fondos. En otros términos, según Iriberri, Patiño no lee o no manda leer la documentación enviada por el tesorero. Además, agrava sus obligaciones al validar deudas dejadas por el tesorero anterior —Díaz Lavandero- con su «páguese» deudas sobre las cuales Iriberri no tenía información previa. La respuesta de Patiño es inapelable. Comentando ahora los estados que preparó para el pago del prest, dice querer evitar «nuevas discusiones, bien entendido que ejecutado así y no en otra forma es mi ánimo que invariable y precisamente se regle Vuestra Señoría a los estados que le dirigí sin idear ni proponerme la más leve alteración» ${ }^{35}$.

Ya que Iriberri sigue en activo hasta 1733, cabe imaginar que la tensión no pasa a mayores. No obstante, estas fricciones llaman la atención sobre un problema de fondo, que ya señaló Verdes Montenegro, antiguo tesorero general. El ministro de Hacienda tiene facultad para enviar órdenes de pago directamente a los responsables de las rentas, sin informar previamente al tesorero general. Este, en tal caso, se entera de los pagos hechos en su nombre una vez verificados estos, preparando a posteriori cartas de pago definitivas. Así trabajó Campoflorido, según Verdes (Dubet, 2015a, pp. 438-443). Patiño no aborda este punto al dar planta a la Tesorería. En las instrucciones de las casas de moneda, distingue las dos vías de pago $^{36}$. No lo hace en las de la renta del tabaco, pero el uso parece similar ${ }^{37}$ (Rodríguez Gordillo, 2008, pp. 90-91, 100-101). También afecta otras rentas, como señala Díaz Lavandero durante su primer ejercicio ${ }^{38}$. Un

Cartas de Iriberri a Patiño, Madrid, 13 y 15/02/1730; respuesta s.f. AGS, SSH, leg. 216-1.

Cartas de 03, 04, 09/03/1730. AGS, SSH, leg. 216-2.

Ordenanza de 16/07/1730, § XVIII, p. 10. AGS, DGT, Inv. 24, leg. 434.

En 1730, Ventura de Bilbao, contador general de la renta, estima el fondo existente en las arcas. Distingue dos tipos de cantidades a deducir, las pagaderas en virtud de cartas de pago del tesorero general y las procedentes de órdenes de Patiño para remitir fondos a tesoreros de provincias. Bilbao a Manuel Ibáñez (oficial de la secretaría de Hacienda), 12/08/1730. AGS, SSH, leg. 1878,

38 Parte de los gastos se hicieron «por órdenes reservadas» que no constan en su Tesorería. Carta de 15/02/1728. En diciembre, dice no saber qué parte de las rentas de 1729 están desembarazadas porque, 
buen conocedor de la Tesorería General, Alejandro de Vega, hostil a Patiño, reconoce aquí un defecto estructural. Así, al elaborar un método «para averiguar los fondos o patrimonio de la corona fundamentalmente y las cargas y obligaciones», señala que además de la información que consta en la Tesorería, es preciso solicitar relaciones de los contadores de cada renta y pedir a la Contaduría General de la Distribución una relación de los fondos consignados en rentas «en virtud de cédulas reales de que no consta en la Tesorería Mayor ni se hace entrada por salida». Así, la Tesorería «está desnuda de las [noticias] que debía tener» ${ }^{39}$. Las reformas del marqués de Ensenada, quien crea varias Direcciones y Contadurías Generales de Rentas obligándolas a comunicar su información a la Tesorería, lo mismo que la Contaduría General de la Distribución, se pueden considerar como una respuesta tardía y eficiente a este problema (Torres Sánchez, 2012).

\section{d) Una acción coherente}

La interpretación de Patiño es distinta: defiende su prerrogativa de poder enviar directamente órdenes de pago a los responsables de las rentas que efectúan pagos en nombre del tesorero general, considerándola indispensable a su credibilidad de ministro. De esta — que no del tesorero general— depende el crédito del rey. Sospecho que por esta razón no resolvió la cuestión planteada por Verdes Montenegro. Esta concepción política del crédito no contradice la dinámica de favores y servicios que une al rey con los hombres de negocios. Así, es compatible con una práctica usada por Campoflorido y repetida por Patiño. Con acreedores selectos, se tolera una merced excepcional: pueden pagar al rey lo que le deben con efectos del tesorero general. Lo que se calla es que adquirieron parte de estos efectos por debajo de su precio nominal, pero es un secreto a voces. Fue lo que se hizo con Iturralde y la renta de Población de Granada en 1725 ya mencionada. Cuando Patiño repite la operación con Santiago, es poco probable que lo haga con candidez. Es la consecuencia lógica de una política tendente a retrasar el pago de los efectos del tesorero dados a los hombres de negocios. De este modo, el ministro utiliza la Tesorería General como una máquina para generar crédito, conociendo el efecto financiero causado, la circulación de los efectos del tesorero entre particulares, con los tráficos anexos. El objetivo del control no es suprimir estos tráficos sino evitar que se disparen para contener la devaluación de los efectos.

Algunas de las opciones institucionales de Patiño merecen releerse a la luz de este proyecto político. Así, mantiene separada de la Tesorería General a la Tesorería

al lado de las que ya fueron objeto de cartas de pago, ciertos libramientos todavía no se tradujeron en cartas de pago y hay «infinitos créditos de toda especie habilitados y mandados pagar». Carta de 09/12/1728. AGS, SSH, leg. 212-1.

39 «Para averiguar [...]», s.f. (1733 o 1738). AHN, E, libro 789. 
de Marina, sobre la cual ejerce su autoridad en calidad de secretario de Marina. Confirma así que la centralización no es un fin en sí. Es una decisión madurada, desde 1722. En 1726, no modifica su posición, aunque ocupa las dos secretarías de Marina y Hacienda (Pérez Fernández-Turégano, 2002; Solbes Ferri, 2014). Supongo que su objetivo es preservarse un margen de autonomía. Por otra parte, las instrucciones de la renta del tabaco de 1726 y las casas de moneda de 1730 realzan la autoridad de Patiño, presentado como el destinatario último de la información contable. Es particularmente significativo el cambio adoptado en las casas de moneda. La reforma, en efecto, confiere los empleos de juez conservador y superintendente general de todas las casas de moneda a los sucesivos secretarios del despacho de Hacienda ${ }^{40}$. Recordamos que, en 1718, el tesorero Hinojosa - quien quería basar el crédito del rey en un tesorero general autónomo - recibió toda la autoridad sobre los superintendentes de las casas de moneda. La comparación ilustra la divergencia entre dos concepciones del crédito y el gobierno de la Hacienda. Esta constancia de Patiño en su propósito de controlar personalmente los caudales del rey para solicitar anticipaciones a hombres de negocios invita a releer otras disposiciones suyas. Así, podríamos preguntarnos si la reforma de la renta del tabaco de 1731 — que pone a toda la renta en administración directa y separa de modo más neto las funciones de gobierno de los directores de las judiciales de la junta—, además de su razón económica, tiene que ver con esta política de crédito (Solbes Ferri, 2008). Asimismo, se sabe poco sobre la preparación y los motivos inmediatos de la puesta en administración directa de la provisión de víveres de tierra en 1730 (Torres Sánchez, 2002).

De todos modos, cabe subrayar la coherencia del proyecto político de Patiño. El tráfico de efectos iniciado en 1734 no es una anomalía. Al contrario, entraba en la categoría de lo posible desde 1726. Esto no resuelve el significado de la crisis de los años 1730, pero es un principio de explicación.

\section{El gobierno de las Haciendas indianas: ¿una adaptación pragmática?}

Existen afinidades, pero no similitud, entre la política peninsular de Patiño y lo que sabemos de su gobierno de las Haciendas indianas. Se observan en tres ámbitos: la relación entre la vía reservada de Indias y la del Consejo de Indias en la corte, la implementación de la primera en los virreinatos y los esfuerzos hechos por utilizar cajas americanas para soportar la creciente deuda del rey.

«Ordenanza [...] para el gobierno de la labor de monedas [...]», Cazalla, 16/07/1730, § 3. AGS, $D G T$, Inv. 24, leg. 434. 


\section{a) Vía del Consejo y vía reservada de Indias}

Dada la ausencia de una separación sistemática entre la correspondencia que Patiño mantiene con las Indias por la vía reservada y la del Consejo, es difícil dilucidar qué espacios reserva a la primera. No solo es una ignorancia de historiador. Observadores coetáneos tienen apreciaciones diversas. Para el marqués de Ensenada, no se aplicó la reforma de 1717 - lo que le permite valorar su propio aporte - (Dubet, 2016b). En cambio, según Alejandro de Vega, «para saber el estado de Indias», se deben recoger las órdenes firmadas por el secretario de Indias desde 1726 y las cédulas y despachos enviados por su vía reservada ${ }^{41}$. El marqués de Casafuerte, virrey de Nueva España (1722-1734), coetáneo de Patiño, debería estar bien informado, pero duda. Así, suele vacilar entre la vía reservada y la del Consejo, enviando al segundo copias de las representaciones hechas al rey por la primera, relativas a asuntos que, según el decreto de 1717 , corresponden al secretario ${ }^{42}$. Su duda no traduce ninguna hostilidad a Patiño, con quien ya compartió convicciones sobre el gobierno territorial en la corona de Aragón ${ }^{43}$. Sí podría reflejar su cautela, dada la reticencia suscitada localmente por la vía reservada. De este modo, en 1731, algunos individuos en México se preguntan si las cartas comunicadas por la vía reservada relativas a la reforma de las casas de moneda, que no llevan la firma real, deben «obedecerse y cumplirse» lo mismo que los despachos y cédulas firmadas. Por supuesto, Casafuerte «dice la repugnancia con que representa esta duda, por no tenerla el virrey» ${ }^{44}$. Pero su prudencia también podría ser una respuesta a la ambigüedad de Patiño. En efecto, este parece querer evitar pronunciarse sobre el reparto de negocios entre Consejo y Secretaría, como cuando combina las dos vías ${ }^{45}$, lo que sigue haciendo incluso desde 1727, cuando el Consejo se encuentra sin cabeza y, por tanto, tal vez más débil que antes (García Pérez, 1998, p. 50; Kuethe y Andrien, 2014; Eissa-Barroso, 2017). Por este doble canal prepara la restauración del virrey de Nueva Granada (Eissa-Barroso, 2017). Asimismo, deja que

41 «Para saber el estado de Indias», s.f. AHN, E, libro 789.

42 Cartas de 08/08/1728, 30/09/1726, 01/10/1726, 05/06/1727, 01 y 18/08/1727, 12/12/1727. AGI, México, leg. 494.

43 Giménez López, 2004; Planas Rosselló y Caimari Calafat, 2006. En 1726, Casafuerte le expresa su «amistad y afecto porque esta no ha sido nunca ceñida a otra cosa que a sus grandes talentos y persona». Casafuerte a Patiño, México, 18/08/1726. AGI, México, leg. 1505

44 «Índice de las representaciones y cartas con que el virrey de Nueva España da cuenta a SM de los negocios del real servicio que ocurren en aquel reino por mano del Excelentísimo Sr don Joseph Patiño [...] secretario del despacho de Indias y Marina [...]», 24/11/1731. Núm. 10. AGI, México, leg. 1505 .

$45 \quad$ En 1732, anuncia por la vía reservada a Casafuerte que se tomó una decisión relativa a los disturbios causados por el visitador Pedro de Contreras, «y que por el Consejo la entenderá». «Índice de las representaciones y cartas con que el marqués de Casafuerte [...] da cuenta a SM [...] de los negocios [...] por mano del Excelentísimo Señor don Joseph Patiño, secretario del despacho de Indias y Marina», núm. 3. AGI, México, leg. 1505. 
la Contaduría del Consejo intente supervisar el estado de los fondos americanos, sin que sepamos de roces entre ella y las nuevas Contadurías Generales (Dubet, 2016b; Sánchez Santiró, 2019).

Sin embargo, podría producirse una evolución. Así, la extensión a Guatemala de la reforma de las casas de moneda iniciada en 1730 se comunica en 1731 por despachos del Consejo de Indias, pero las órdenes de 1734 pasan por la vía reservada ${ }^{46}$. A mediados de esta década, las explicaciones dadas al virrey de Nueva España sobre la aplicación de la reforma en México también proceden del secretario ${ }^{47}$. En 1735, la reforma de la superintendencia de los azogues de Perú, lo veremos, pasa por la vía reservada. También durante el ministerio de Patiño es cuando se crean dos mesas para la venalidad de oficios dentro de la Secretaría de Indias (Burgos Lejonagoitia, 2015, pp. 237-246). Convendría allegar elementos complementarios para saber si Patiño preserva la ambigüedad hasta 1736 o va afirmando, al filo de los años, la preeminencia de la vía reservada.

\section{b) Virreyes y superintendentes}

En el espacio americano, Patiño, como Alberoni, parece vacilar entre reforzar las facultades de los virreyes en el gobierno de la Hacienda debajo de su autoridad de secretario o crear figuras de comisarios independientes de los virreyes, en relación directa con la vía reservada. Compone asimismo de modo variable con las Audiencias y Tribunales de Cuentas. Así, en Perú, la pervivencia de los superintendentes del ramo de azogues — que no dependen del secretario, sino de un superintendente general elegido dentro del Consejo - podría ser el fruto de un compromiso con la Audiencia, ya que desde 1722 se turnan los oidores para ejercer la comisión (Pearce, 1999). Aparentemente, el marqués de Castelfuerte, virrey (1723-1736), acompaña la reforma (Moreno Cebrián, 2000). Solo en enero de 1735, Patiño instituye un «gobernador y superintendente general de las minas de Huancavelica y ramo de azogues» independiente de la Audiencia y del virrey, decisión comunicada por su vía reservada. El pretexto es práctico — el virrey está demasiado ocupado para ejercer la «vigilancia continua» necesaria - La reforma se inscribe en la ya observada tendencia a preferir ministros individuales «inteligentes»: se necesita de un experto mejor formado que los letrados de la Audiencia, eligiéndose al actual superintendente de la mina de Almadén (Pearce, 1999)

\footnotetext{
$46 \quad$ Patiño a Antonio Pedro de Echeverz y Subirá, presidente de la Audiencia de Guatemala, 17/01/1734 y 19/07/1735. AGI, Indiferente, leg. 543, lib. 1, fols. 36-50.

47 Patiño a Casafuerte, 25/07/1735. AGI, Indiferente, leg. 543, lib. 1, fols. 65-69.

48 AGI, Indiferente, leg. 542, lib. 3, órdenes y cédulas de 22/01/1735.
} 
En Nueva España, en cambio, Patiño fortalece al virrey en el gobierno de la Hacienda, dándole la distribución de los fondos. La cuestión se discute entre el virrey, el Tribunal Mayor de Cuentas y los oficiales de la caja real de México desde fines del siglo XVII (Sánchez Santiró, 2019). En 1725, las acusaciones son recíprocas. Según el Tribunal de Cuentas, Casafuerte decidió a solas una «mutación de libranzas» y manifestó una «soberanía» inoportuna dejando en libertad a un sujeto perseguido por fraudes ${ }^{49}$. El virrey responde que los oficiales reales sacan un «beneficio» ilícito del pago de las libranzas, extorsionando «premio» a los acreedores del rey, una práctica común según los visitadores, porque las libranzas se pagan fuera del control del virrey (Gómez, 1979; Bertrand, 2011). Le corresponde, puntualiza, distribuir los fondos en su calidad de «superintendente general de Real Hacienda» del reino ${ }^{50}$. Este título, que no suele usarse en la documentación oficial antes de la reforma de Ensenada, parece reflejar una reivindicación de Casafuerte y de algunos otros individuos en un momento de debates sobre las facultades de gobierno de la Hacienda de los virreyes ${ }^{51}$ (Sánchez Santiró, 2013). Como consecuencia, el virrey pide una cédula que obligue a los oficiales reales a dirigirse a él para que «este mande hacer los pagamentos que fuere del agrado de Vuestra Majestad mandar se ejecuten». En cuanto al Tribunal de Cuentas, no debería poder pasar «en data ninguna libranza [...] que no tenga el páguese del virrey» ${ }^{52}$. La respuesta de Madrid, comunicada por Patiño, es favorable (Sánchez Santiró, 2019). En el caso de las casas de moneda, Patiño también refuerza la competencia del virrey. Como muestra Michel Bertrand, desde la puesta en obra de la reforma de la casa de moneda de México, en 1731, los roces son constantes entre el superintendente de esta, en principio independiente del virrey, y Casafuerte. Después de la muerte de este, Felipe V resuelve la cuestión a favor del virrey, subordinándole el superintendente para «todo lo gobernativo, económico, directivo y providencial». En particular, los virreyes deberán estar informados verbalmente o por escrito sobre toda la actividad de una «oficina» que maneja tantos fondos ${ }^{53}$. En 1738, se confiará el nombramiento del superintendente al virrey (Bertrand, 2011).

El Tribunal al rey, México, 01 y 10/05/1725. AGI, México, leg. 733.

«si los oficiales reales de las cajas han de tener por sí facultad para satisfacer a los acreedores sin orden del superintendente general de Real Hacienda que es el virrey, no se podrá este hacer responsable ni de la falta que puede experimentarse en la asistencia de ministros [...] ni tampoco de la administración de real Hacienda». Casafuerte a Felipe V, México, 19/09/1726. AGI, México, leg. 495. En 1702, Francisco Seijas propuso crear nuevos virreinatos y, en los más, instituir un superintendente general distinto del virrey, aunque en el de Chiapas se daría el empleo al virrey. Pérez-Mallaína Bueno, 1986, pp. 57-63, 127-133. En 1710, al contrario, el marqués de Alburquerque, virrey de Nueva España, también se intitulaba superintendente general de la Hacienda real, por lo que criticaba la creación de una «intendencia de los azogues en otra mano». Norman Martín, 2010, p. 90. Casafuerte a Felipe V, México, 19/09/1726. AGI, México, leg. 495.

«Vuestra Majestad declara la forma en que se debe entender la subordinación del superintendente [...]». 25/07/1735. AGI, Indiferente, leg. 543, lib. 1, fols. 65-69. 
Asimismo, cuando, en 1732, Casafuerte reclama, de acuerdo con los contadores del Tribunal de Cuentas, la supresión del cargo de regente de este cuerpo, Patiño y el Consejo de Indias le dan la razón (Baeza Martín, 2011). En cambio, se mantiene en Nueva España un superintendente de azogues dotado de una amplia autonomía respecto al virrey, soportado por Madrid por lo menos hasta 1728. Aquel año, Casafuerte señala que toleró sus «procedimientos» sin protestar desde 1724, pero el superintendente, Joseph de Uribe, incurrió en una «monstruosidad», exigiendo que las cajas reales le remitieran certificaciones del valor de los derechos sobre la plata y su distribución. La facultad es «tan ofensiva a la del virrey como se comprehende y que solo está reservada a la suprema autoridad de Vuestra Majestad o a quien fuere servido delegarla o conferirla expresamente». En este caso, Casafuerte elige la vía del Consejo para comunicar su denuncia ${ }^{54}$. ¿Esperaría de él mayor comprensión que en Patiño? Aparentemente, este conflicto de competencias se resuelve a favor del superintendente de azogues, como relata José de Gálvez a posteriori ${ }^{55}$.

En suma, en el gobierno de las Haciendas virreinales, la política de Patiño no sigue una línea simple. No depende solo de la relación personal del ministro con los virreyes ${ }^{56}$. Parece construirse sector por sector, en función de equilibrios de poder locales, importando más el fin —un control sobre el manejo de los fondos que permita informar a Madrid - que las vías institucionales.

\section{c) Dinero de Indias y crédito real}

Donde Patiño tiene un proyecto definido es en la reforma de las casas de moneda y, desde 1735, la de la superintendencia de azogues. En ambos casos, su política, basada en órganos uniformes para toda la monarquía, recuerda la de Alberoni. En el caso de las casas de moneda, ya la ordenanza de junio de 1728 , que modifica la ley de los metales y regula la actividad de los oficiales, prevé un control sobre las cecas americanas — se enviarán muestras a España donde se analizarán los metales- A 29 de junio, el Consejo de Indias envía el texto, firmado por Patiño, al virrey de Nueva España — probablemente también lo reciben el de Perú y los demás presidentes de Audiencias- . Al día siguiente, el ministro escribe a Casafuerte de su puño y letra, diciéndose obligado a usar de la vía reservada, para manifestarle la sorpresa del rey ante la inobservancia de las ordenanzas sobre moneda en su reino, e instándole a ser

$54 \quad$ Casafuerte a Felipe V, México, 15/09/1728. AGI, México, leg. 496.

55 En su informe de 31/12/1771, explica que desde 1730 el ramo está confiado a un superintendente privativo elegido en la Audiencia. Gálvez, 1771, p. 75.

56 Como en el caso de Casafuerte, la relación de Castelfuerte con Patiño es buena. Moreno Cebrián, 2000 . 
contundente en la represión de fraudes ${ }^{57}$. La reforma de julio de 1730 completa el proyecto, proponiéndose poner la acuñación de moneda en administración directa, bajo la autoridad, como vimos, de un nuevo superintendente general y juez conservador, el propio secretario de Hacienda. Para conducirla, se crea una Junta de Moneda, en noviembre, sustituyéndola en diciembre una Junta de Comercio y Moneda, producto de la fusión con la Junta de Comercio previa. La preside el secretario del despacho de Hacienda en su calidad de superintendente general de las casas de monedas, extendiéndose en seguida la competencia de la junta a las Indias (Larruga, 1789, t. IV, Memoria XXV; Pérez-Fernández Turégano, 2006, pp. 209-213). En México, la reforma se aplica incorporándose los oficios venales a la Hacienda (Bertrand, 2011). En este caso, Patiño tiene la firme intención de proceder de modo uniforme en la monarquía. Así, se invita al virrey de Perú a imitar a México (Moreno Cebrián, 1983, p. 373). En cuanto al presidente de Guatemala, Patiño le reconviene por no imitar a México y Lima en la elección del superintendente ${ }^{58}$. Esta identidad entre reinos resulta ambivalente. En efecto, se explica la subordinación del superintendente de la casa de moneda de México a su virrey por el paralelo con las casas de España, subordinadas al «superintendente general de los ingenios y casas de estos reinos $>{ }^{59}$ : la similitud equipara a cada virrey con este, pero contradice el esquema dado por la Junta — que subordina todas las casas de moneda de la monarquía a un único superintendente, Patiño- . Aun así, queda en pie la idea de que una misma forma de gobierno coordinada por una sola Junta puede funcionar en toda la monarquía.

El modelo también parece valer para la superintendencia de azogues de Perú. En efecto, no solo se busca exportar a Huancavelica la experiencia de empleados de Almadén. Una semana después de la ordenanza de Perú, a 30 de enero de 1735, se publica otra para «para el gobierno de las fábricas y minas de azogue del Almadén» (Dobado González, 1989, pp. 215-6; Bermejo Cabrero, 2001). La coincidencia temporal invita a creer que, aquí también, se quisieron uniformar reglas de organización y control.

En ambos casos, el objetivo es elevar productos disponibles. Ahora bien, la forma de distribución de esta futura riqueza tiene que ver con el modo de gestión del crédito predilecto de Patiño. En el caso del azogue peruano, el ministro explica al nuevo superintendente virreinal que la existencia de una cuenta separada de los otros ramos de la Hacienda le permitirá conocer el «beneficio» de su ramo, elaborar relaciones quinquenales de su producto e informar sobre la distribución del azogue

Felipe V a Andrés de Elcorobarrutia (con copia para Casafuerte), 29/06/1730. Patiño a Casafuerte, 30/06/1728. AGI, Indiferente, leg. 542, lib. 3, fols. 62-68 y 68-70.

58 Patiño a Echeverz y Subirá, 17/01/1734. AGI, Indiferente, leg. 543, lib. 1, fols. 7-10.

$59 \quad$ Cfr. la nota 53.-5 
y la recaudación de dinero ${ }^{60}$. Sería deseable saber si la ordenanza de Almadén prevé lo mismo ${ }^{61}$. En el caso de las casas de moneda, se supone que lo descrito para España se aplica. En otros términos, como en España, Patiño debe ser el receptor de una información contable cuyo fin es calcular disponibilidades. El objetivo es soportar el crédito del rey. Así, como indica la ordenanza de 1728, los metales que vengan de las Indias para el rey se traerán a las casas de moneda de Madrid y Segovia, mientras que los de particulares irán a Sevilla — en este caso, Patiño cuenta con los derechos sacados de su acuñación - ${ }^{62}$. Ya vimos qué uso se hace de las cartas de pago del tesorero general sobre estas casas. De este modo, al incluir a las casas de moneda americanas en la reforma de 1728-1730, Patiño parece quererlas absorber en el sistema de crédito descrito arriba. La forma de control no es idéntica a la peninsular, ya que el tesorero general no tiene autoridad sobre las casas de moneda americanas - por lo que urge conocer el estado de los fondos y transportarlos a Sevilla- No obstante, parece ser que, para Patiño, lo más importante es su propio control de ministro.

\section{Conclusiones}

El estudio de los proyectos y la práctica de Patiño obliga a corregir la visión de la creciente influencia de la vía reservada en el gobierno de la Hacienda en España y en las Indias como un proceso lineal de sustitución del gobierno colegial. En efecto, este perduró con equilibrios variables. Además, la vía reservada no significó lo mismo para todos sus promotores. En España, se podía asociar a formas opuestas de relación con la gente de negocios. En las Indias, su traducción institucional podía consistir en potenciar a los virreyes convirtiéndolos en instrumentos del ministro o, en cambio, cortocircuitarlos: aquí, Patiño fue tan ambivalente o pragmático como sus predecesores.

El estudio también lleva a matizar la idea de una centralización motivada por la racionalización y encaminada a restringir los beneficios de los agentes del rey o los hombres de negocios en la Hacienda real. En el caso de la Tesorería General, aunque se conformó una oficina más eficaz que antes en la producción de información contable, el control del gasto y el nivel de la deuda corriente, estos fueron más bien medios que fines. Patiño buscaba ante todo conferir credibilidad al ministro, cuyo compromiso político era la principal garantía del crédito del rey. Esta credibilidad dependía de dos condiciones: que el ministro accediera a una información fiable sobre los fondos que distribuía (que la Tesorería fuera eficaz) y que impusiera su autoridad

Título de Jerónimo de Sola, 22/01/1735. AGI, Indiferente, leg. 542, lib. 3.

No pudo consultarse.

Ordenanza de 09/06/1728, § XIX. AGS, DGT, Inv. 24, leg. 434. 
al tesorero. La segunda condición, tal como la entendió Patiño, le llevó a tomar decisiones sin consultar al tesorero, pudiendo poner en peligro la capacidad de pago de este, por lo que era indispensable que ministro y tesorero tuvieran una comunicación fluida. Además, controlar la deuda no significaba abolir del todo sus malos usos sino conseguir que esta deuda no creciera a espaldas del ministro y este pudiera elegir a sus beneficiarios (el monarca incluido), propósito compatible con la participación de poderosos grupos privados.

Esta concepción del papel del ministro como artífice del crédito real explica rasgos de la política americana de Patiño. Como en España, lo importante fue que el ministro consiguiera información fiable sobre el estado de los fondos. Por eso encontramos indicios de un incremento de la vía reservada en cuestiones de Hacienda, aunque fue a todas luces más prudente que en el caso de la Hacienda peninsular, probablemente porque el Consejo de Indias no fue tan debilitado como el de Hacienda (García Pérez, 1998; Dedieu, 2000). No obstante, en el caso americano, la acción de Patiño fue selectiva, guiada por el imperativo del crédito: a sabiendas de que la mayor parte del producto de la fiscalidad se gastaba in situ, se concentró en los ramos que sí permitirían elevar en breve las remesas a la Depositaría de Indias, cuyos fondos solía destinar a pagar deudas en España. 


\section{Bibliografía}

AbBad, Fabrice, y Ozanam, Didier (1992), Les intendants espagnols du XVIII siècle, Madrid, Casa de Velázquez.

Albareda, Joaquim (2018), «Fragmentos de Estado. España en el siglo XVIII», Magallánica, 5-9, pp. 1-149.

Alcaraz Gómez, José (1995), Jesuitas y reformismo. El padre Francisco de Rávago, Valencia, Facultad de Teología de San Vicente Ferrer.

Andúuar Castillo, Francisco (2008), Necesidad y venalidad. España e Indias, 1704-1711, Madrid, Centro de Estudios Políticos y Constitucionales.

Andújar Castillo, Francisco y María del Mar Felices de la Fuente (eds., 2011), El poder del dinero. Ventas de cargos y honores en el Antiguo Régimen, Madrid, Biblioteca Nueva.

Andújar Castillo, Francisco y Ponce Leiva, Pilar (eds., 2016), Mérito, venalidady corrupción en España y América, siglos XVII y XVIII, Valencia, Albatros.

Aquerreta, Santiago (2001), Negocios y finanzas en el siglo XVIII: la familia Goyeneche, Pamplona, EUNSA.

BAEZA Martín, Ascensión (2001), El marqués de Casafuerte, virrey de Nueva España, Tesis Doctoral Inédita, Universidad de Sevilla.

Baeza Martín, Ascensión (2011), «Creación y reformas de un oficio inestable. El regente del tribunal de cuentas de México (1708-1781)», Temas americanistas, 27, pp. 1-24.

Bermejo CABrero, José Luis (2001), «Juntas y superintendencias de minas (siglos XVII-XVIII)», Anuario de Historia del Derecho Español, 71, pp. 75-122.

Bertrand, Michel (2011), Grandeza y miseria del oficio. Los oficiales de la Real Hacienda de la Nueva España, siglos XVII y XVIII, Fondo de Cultura Económica, México. $<$ https://doi.org/10.4000/books.cemca.1128>.

Birocco, Carlos María (2017), «Puertas y llaves. Reconfiguración de los vínculos entre gobernadores y vecinos en Buenos Aires a partir de las reformas borbónicas tempranas», Anuario del Instituto de Historia Argentina, 17-2, pp. 1-20. $<$ https://doi.org/10.24215/2314257Xe048>.

Burgos Lejonagoitia, Guillermo (2015), Gobernar las Indias. Venalidad y méritos en la provisión de cargos americanos, 1701-1746, Almería, Universidad de Almería.

Canga Argüelles, José (1833-1834), Diccionario de hacienda con aplicación a España, Madrid, Imprenta de don Marcelino Calero y Portocarrero.

CARo BARoja, Julio (1985), La hora navarra del XVIII (personas, familias, negocios e ideas), Pamplona, Comunidad Foral de Navarra. 
Castro, Concepción de (2004), A la sombra de Felipe V. José de Grimaldo, ministro responsable (1703-1726), Madrid, Marcial Pons.

DediEu, Jean-Pierre (2000), «La Nueva Planta en su contexto. Las reformas del aparato del Estado en el reinado de Felipe V», Manuscrits, 18, pp. 113-139.

Dedieu, Jean-Pierre (2011), «Les groupes financiers et industriels au service du roi Espagne. Fin XVII - début XVIII ${ }^{\mathrm{e}}$ siècle», en Dubet, Anne y Luis, Jean-Philippe (eds.), Les financiers et la construction de l'Etat en France et en Espagne (milieu du XVII siècle-milieu du XIX' siècle), Rennes, PUR. <https://doi.org/10.4000/ books.pur.124353>.

Dedieu, Jean-Pierre (2012), «Les intermédiaires privés dans les finances royales espagnoles sous Philippe V et Ferdinand VI», en Meyzie, Vincent (ed.), Crédit public, crédit privé et institutions intermédiaires. Monarchie française, monarchie hispanique, XVI ${ }^{e}$-XVIII ${ }^{e}$ siècles, Limoges, PULIM, pp. 223-239.

Dedieu, Jean-Pierre (2014), «El núcleo y el entorno : la Real hacienda en el siglo XVIII», Espacio, Tiempo y Forma, 27, pp. 161-179. <https://doi.org/10.5944/ etfiv.27.2014.13705>.

Delgado Barrado, José Miguel (2007), Aquiles y Teseos. Bosquejos del reformismo borbónico (1701-1759), Universidad de Granada-Universidad de Jaén.

Delgado Ribas, Josep M. (2007), Dinámicas imperiales (1650-1796). España, América y Europa en el cambio institucional del sistema colonial español, Barcelona, Bellaterra.

Dobado GonzáLez, Rafael (1989), El trabajo en las minas de Almadén, Tesis Doctoral Inédita, Universidad Complutense de Madrid.

Dubet, Anne (2012), «La construcción de un modelo de control de la Hacienda en el primer tercio del siglo XVIII. El proyecto de José Patiño (1724-1726)», De Computis, 16, pp. 7-54. <https://doi.org/10.26784/issn.1886-1881.v9i16.87>.

DuBET, Anne (2013), «José Patiño y el control de la Hacienda ¿Una cultura administrativa nueva?», en López Díaz, María (dir.), Elites y poder en las monarquías ibéricas: del siglo XVIII al primer liberalismo, Madrid, Biblioteca Nueva, pp. 39-55

Dubet, Anne (2015a), La Hacienda Real de la Nueva Planta (1713-1726), entre fraude y buen gobierno. El caso Verdes Montenegro y las reformas de la Hacienda, Madrid, Fondo de Cultura Económica.

DuBET, Anne (2015b), «Entre razón y ciencia de la Hacienda: la conflictiva construcción de un modelo de buen gobierno de la Real Hacienda en España en la primera mitad del siglo XVIII», Espacio, Tiempo y Forma, 28, pp. 187-209. <https://doi. org/10.5944/etfiv.28.2015.14204>.

Dubet, Anne (2016a), «Entre servicio del rey y tráfico de efectos: la doble negociación de Juan Bautista de Iturralde», Librosdelacorte.es, 13, Otoño-invierno, 
pp. 8-40. <https://repositorio.uam.es/bitstream/handle/10486/676370/LC_13_1. pdf? sequence $=1 \&$ isAllowed $=\mathrm{y}>$.

Dubet, Anne (2016b), «El control del 'Ministro de Hacienda' de Indias: el Marqués de Ensenada, las cuentas y las cajas americanas (1743-1754)». De Computis, Diciembre, 25, pp. 35-64. <https://doi.org/10.26784/issn.1886-1881.v13i25.252>.

Dubet, Anne (2017), «La suspensión de pagos de 1739: ¿una medida de 'buen gobierno’ de la Hacienda?», Espacio, Tiempo y Forma, 30, pp. 19-56. <https:// doi.org/10.5944/etfiv.30.2017.18588>.

Dubet, Anne, y Solbes Ferri, Sergio (2019), El rey, el ministro y el tesorero. El gobierno de la Real Hacienda en el siglo XVIII español, Madrid, Marcial Pons.

EISSA-BARroso, Francisco (2016), «De corregimiento a gobierno político-militar: el gobierno de Veracruz y la 'militarización' de cargos de gobierno en España e Indias durante los reinados de Felipe V», Relaciones. Estudios de Historia y Sociedad, 37-147, pp. s/n. <https://doi.org/10.24901/rehs.v37i147.174>.

EISSA-BArroso, Francisco (2017), The Spanish Monarchy and the Creation of the Viceroyalty of New Granada (1717-1739). The Politics of Early Bourbon Reform in Spain and Spanish America, Leiden-Boston, Brill. <https://doi. org/10.1163/9789004308794 $\geq$.

Eissa-Barroso, Francisco, y Vázquez Varela, Ainara (eds., 2013), Early Bourbon Spanish America. Politics and Society in a forgotten Era (1700-1759), LeidenBoston, Brill. <https://doi.org/10.1163/9789004253155>.

EsCAMILla, Iván (2011), Los intereses malentendidos: el consulado de comerciantes de México y la monarquía española, 1700-1739, México, UNAM.

EsCOBEDo Romero, Rafael (2007), El tabaco del rey. La organización de un monopolio fiscal durante el Antiguo Régimen, Pamplona, EUNSA.

Escudero, José Antonio (2001), Los orígenes del Consejo de Ministros en España. La junta suprema de Estado, Madrid, Editorial Complutense.

Garate Ojanguren, Montserrat (1990), La Real Compañia Guipuzcoana de Caracas, San Sebastián, SGEP.

García Gaínza, María Concepción (ed., 1999), Juan de Goyeneche y su tiempo. Los navarros en Madrid, Pamplona, Gobierno de Navarra.

GARCía PÉrEz, Rafael (1998), El Consejo de Indias durante los reinados de Carlos III y Carlos IV, Pamplona, EUNSA.

Gay EscodA, Josep-María (1982), «La gènesi del Decret de Nova Planta de Catalunya. Edició de la consulta original del Consejo de Castilla de 13 de juny de 1715», Revista jurídica de Catalunya, I, pp. 7-348. 
GiLdas, Bernard (1972), Le secrétariat d'Etat et le Conseil espagnol des Indes (1700-1808), París-Ginebra, Droz.

GimÉNEZ LóPEZ, Enrique (1994), «El debate civilismo-militarismo y el régimen de Nueva Planta en la España del siglo XVIII», Cuadernos de Historia Moderna, 15, pp. 41-75.

Giménez LóPEz, Enrique (2004), «Marte y Astrea en la corona de Aragón. La preeminencia de los capitanes generales sobre los togados en los primeros años de la nueva planta», Revista de Historia Moderna, 22, pp. 69-90. $<$ https://doi. org/10.14198/RHM2004.22.08>.

GLESENER, Thomas (2018), L'empire des exilés. Les Flamands et le gouvernement de l'Espagne au XVIII' siècle, Madrid, Casa de Velázquez.

Gómez, Amalia (1979), Las visitas de la real Hacienda novohispana en el reinado de Felipe $V$, Sevilla, CSIC.

GonzÁlez Enciso, Agustín (2000), «Los usos financieros del tabaco; o bien, para qué servían los dineros obtenidos con la Renta del Tabaco», en Solbes Ferri, Sergio, Laforet Hernández, Juan José y Luxán Meléndez, Santiago de (eds.), El mercado del tabaco en España durante el siglo XVIII: fiscalidad y consumo, Las Palmas, Universidad de las Palmas de Gran Canaria, pp. 25-52.

GonzÁlez Enciso, Agustín (ed., 2007), Navarros en la Monarquía española en el siglo XVIII, Pamplona, EUNSA.

González Enciso, Agustín (ed., 2008), Política económica y gestión de la renta del tabaco en el siglo XVIII, Madrid, Los libros de Altadis.

Guerrero Elecalde, Rafael e Imízcoz Beunza, José María (2012), «Negocios y clientelismo político. Los empresarios norteños en la economía de la monarquía borbónica», en Ocampo Suárez Valdés, Joaquín (ed.), Empresas y empresarios en el norte de España (siglo XVIII), Somonte-Cenero, Editorial Trea, pp. 331-362.

GUERRERo ElECALDE, Rafael (2012), Las elites vascas y navarras en el gobierno de la Monarquía borbónica: Redes sociales, carreras y hegemonía en el siglo XVIII (1700-1746), Bilbao, Universidad del País Vasco.

Heredia Herrera, Antonia (1989), «México», en Navarro García, Luis (coord.), Historia General de España y América. Tomo 11-1: América en el siglo XVIII. Los primeros Borbones, Madrid, Rialp, pp. 461-517.

Imízcoz Beunza, José María, «Las élites del reformismo borbónico: una historia social», Magallánica, 4-7, 2017, pp. 1-214.

KAMEN, Henry (1964), «El establecimiento de los intendentes en la administración española», Hispania, XXIV, pp. 368-395.

Kuethe, Allan J. (2013), «Cardinal Alberoni and Reform in the American Empire», en Eissa-Barroso, Francisco A. y Vázquez Varela, Ainara (eds.), Early Bourbon 
Spanish America: Politics and Society in a Era (1700-1759), Leiden, Brill, pp. 23-38. <https://doi.org/10.1163/9789004253155_004>.

Kuethe, Allan J. y Andrien, Kenneth J. (2014), The Spanish Atlantic World in the Eighteenth Century. War and the Bourbon Reforms, 1713-1796, Cambridge, Cambridge University Press. <https://doi.org/10.1017/CBO9781107338661>.

LARRUGA, Eugenio (1789), Memorias políticas y económicas sobre los frutos, comercio, fábricas y minas de España, con inclusión de los reales decretos, órdenes, cédulas, aranceles y ordenanzas expedidas para su gobierno y fomento, Madrid, por don Antonio Espinosa, t. 4.

LaVAllé, Bernard (ed., 2012), Los virreinatos de Nueva España y del Perú (1680-1740). Un balance historiográfico, Madrid, Casa de Velázquez

Máqueda Abreu, Consuelo (2009), Alberoni: entorno juridico de un poder singular, Madrid, UNED.

MARChENA, Juan (2012), «De la guerra antigua a la guerra moderna: las reformas militares en el Caribe (1700-1739)», en Lavallé, Bernard (ed.), El primer siglo XVIII en Hispanoamérica, Toulousse, Éditions Meridiennes, pp. 159-202.

Martín, Norman (2018), «Biografía del virrey de la Nueva España, don Francisco Fernández de la Cueva Enríquez, segundo duque de Alburquerque, y las instrucciones y memoria de su gobierno (1702-1711)», en Torre Villar, Ernesto de la (ed.), Dos documentos virreinales. Las instrucciones al virrey Luis de Velasco II y las instrucciones y memoria del segundo duque de Alburquerque, Coyoacán, Instituto de Investigaciones Históricas-UNAM, pp. 38-91. <http:// www.historicas.unam.mx/publicaciones/publicadigital/libros/517/517_04_04_ BiografiaVirrey.pdf $>$.

Moreno Cebrián, Alfredo (ed., 1983), Conde de Superunda. Relación de gobierno de Perú (1745-1761), Madrid, CSIC.

Moreno Cebrián, Alfredo (2000), El virreinato del Marqués de Castelfuerte, 1724-1736: el primer intento borbónico por reformar el Perú, Madrid, Catriel.

PeArCe, Adrian (1999), «Huancavélica 1700-1759: Administrative Reform of the Mercury Industry in Early Bourbon Peru», The Hispanic American Historical Review, 79-4, pp. 669-702. <https://doi.org/10.1215/00182168-79.4.669>.

Peralta Ruiz, Víctor (2006), Patrones, clientes y amigos. El poder burocrático indiano en la España del siglo XVIII, Madrid, CSIC.

PÉrez Fernández-TuréGano, Carlos (2002), «La fiscalización económica en la Marina española del siglo XVIII», en Teijeiro de la Rosa, Juan Miguel (ed.), La Hacienda militar. 500 años de intervención en las fuerzas armadas, Madrid, Ministerio de Defensa, pp. 305-424. 
Pérez Fernández-Turégano, Carlos (2006), Patiño y las reformas de la administración en el reinado de Felipe $V$, Madrid, Ministerio de Defensa.

Planas Rosselló, Antonio y CAimari Calafat, Tomeu (2006), «Una relación reservada del marqués de Casa Fuerte a su sucesor en la Capitanía General de Mallorca (1721)», Bolletí de la Societat Arqueològica Lul·liana: Revista d'estudis històrics, 62, pp. 69-112.

Pulido Bueno, Ildefonso (1998), José Patiño: el inicio del gobierno político-económico ilustrado en España, Huelva, Artes Gráficas Andaluzas.

RodríGuez GordiLlo, José M. (2008), «El pensamiento de los economistas españoles y la Renta del Tabaco en la primera mitad del siglo XVIII»»», en González Enciso, Agustín (ed.), Política económica y gestión de la Renta del Tabaco, Madrid, Fundación Altadis-Ediciones El Umbral, pp. 29-119.

Sallés Vilaseca, Núria (2016), Giulio Alberoni y la dirección de la política española después de los tratados de Utrecht (1715-1719), Tesis Doctoral Inédita, Universidad Pompeu Fabra.

Sallés Vilaseca, Núria (2018), «Los secretarios del despacho y el Consejo de Gabinete de Felipe V: diseños de una Nueva Planta en la administración central», Magallánica, 5/9, pp. 7-38.

SÁNCHEZ SANTIRó, Ernest (2019), «La reforma de los mecanismos de control en la Real Hacienda de Nueva España (siglos XVI-XVIII)», Anuario de Estudios Americanos, 76-1, pp. 209-236. < https://doi.org/10.3989/aeamer.2019.1.09>.

SÁNCHEZ SANTIRó, Ernest (ed., 2015), El gasto público en los imperios ibéricos, siglo XVIII, México, Instituto de Investigaciones D. José María Luis Mora.

Solbes Ferri, Sergio (2008), «Estrategias de gestión de la renta del tabaco, 1726-1736. El gobierno de Patiño y la introducción de la administración directa», en González Enciso, Agustín (ed.), Política económica y gestión de la Renta del Tabaco, Madrid, Fundación Altadis-Ediciones El Umbral, pp. 121-173.

Solbes FerRI, Sergio (2014), «El control del gasto de la Marina española en las Secretarías de Estado y del Despacho. Los pagos dependientes de la Tesorería General en la primera mitad del XVIII», en Baudot, María (ed.), El Estado en guerra. Expediciones navales españolas en el siglo XVIII, Madrid, Polifemo, pp. 147-194.

SolbeS FERRI, Sergio (2016), «El delicado tránsito entre recaudación de rentas y ejecución del gasto. La renta del tabaco y la Tesorería General a mediados del siglo XVIII», De Computis, 13-25, pp. 137-160. < https://doi.org/10.26784/ issn.1886-1881.v13i25.256>.

Storrs, Christopher (2016), The Spanish Resurgence, 1713-1748, Yale University Press. $<$ https://doi.org/10.12987/yale/9780300216899.001.0001>. 
TARRAGÓ, Griselda (2012), «Espacio, recursos y territorio. La gobernación del Río de la Plata durante el reinado de Felipe V», en Ruiz Ibáñez, José Javier y Mazín, Óscar (eds.), Las Indias Occidentales. Procesos de incorporación territorial a las Monarquías Ibéricas, México, El Colegio de México, pp. 283-327.

TeijeIro de la Rosa, Juan Miguel (ed., 2002), La Hacienda militar. 500 años de intervención en las fuerzas armadas, Madrid, Ministerio de Defensa.

Torres SÁnchez, Rafael (2006), «Public Finances and Tobacco in Spain for the American War of Independence», en Bowen Huw V. y González Enciso, Agustín (eds.), Mobilising Resources for War: Britain and Spain at Work During the Early Modern Period, Pamplona, EUNSA, pp. 191-224.

Torres SÁnchez, Rafael (2012), La llave de todos los tesoros. La tesorería general de Carlos III, Madrid, Sílex.

Torres SÁnchez, Rafael (2013), El precio de la guerra. El Estado fiscal-militar de Carlos III (1779-1783), Madrid, Marcial Pons.

TORRES SÁNCHEZ, Rafael (2016), «Alimentando a Marte: la política de suministros militares al ejército español en el XVIII», Cuadernos De Historia Moderna, 41(2), pp. 373-389. <https://doi.org/10.5209/CHMO.53816>.

TORRes SÁnchez, Rafael (ed. 2010), Volver a la «hora Navarra». La contribución Navarra a la construcción de la monarquía española en el siglo XVIII, Pamplona, EUNSA.

Torres SÁNCHEZ, Rafael (ed., 2013), «El negocio de la guerra: la movilización de recursos militares y la construcción de la monarquía española (XVII y XVIII)», Studia Historica. Historia moderna, 35, pp. 23-303. <https://doi.org/10.14201/ shhmo201335159199>.

VÁzQuez Gestal, Pablo (2013), Una nueva majestad. Felipe V, Isabel de Farnesio y la identidad de la monarquía (1700-1729), Madrid, Marcial Pons. 
